\title{
Effect of Prophylactic Ketoconazole and Nystatin on Fungal Flora
}

\author{
Wirkung von prophylaktischen Ketoconazol- und Nystatin- \\ Gaben auf die Pilzflora
}

\author{
C. A. Kauffman, P. G. Jones', A. G. Bergman, \\ L. S. McAuliffe ${ }^{2}$, and M. K. Liepman ${ }^{3}$.
}

Divisions of Infectious Diseases and Hematology-Oncology Department of Internal Medicine, University of Michigan Medical School and Veterans Administration Medical Center Ann Arbor, Michigan

IPresent address: Division of Infectious Diseases M. D. Anderson Hospital Houston, Texas 2Present address: East Main Street Medical Associates Hyannis, Massachusetts 3Present address: Division of Medical Oncology University of Massachusetts Medical School Worchester, Massachusetts

Key words: Ketoconazole - nystatin - antifungal drugs - antifungal prophylaxis neutropenic patients - yeast infections

Schlüsselwörter: Ketoconazol - Nystatin - Antimykotika - antimykotische Prophylaxe neutropenische Patienten - Hefeinfektionen

Summary: The effect of prophylactic antifungal drugs on oropharyngeal and anterior nares fungal colonization was studied in 20 patients receiving nystatin and 19 patients receiving ketoconazole. Surveillance cultures were obtained weekly for a mean of $27.1 \pm 4.8$ days in the nystatin group and $44.0 \pm 6.7$ days in the ketoconazole group. Initially, $63.2 \%$ of nystatin patients and $\mathbf{7 7 . 8} \%$ of ketoconazole patients had yeasts in their oropharynx. Neither drug eliminated oropharyngeal yeast colonization; by the end of the first four weeks of surveillance, $66.7 \%$ of the nystatin group and $63.6 \%$ of the ketoconazole group still had yeasts in the oropharynx. However, both drugs caused a reduction in the quantity of yeasts grown on successive cultures. Filamentous fungi were isolated in baseline cultures in $42.1 \%$ of the nystatin patients and $33.3 \%$ of the ketoconazole patients. Prophylaxis did not appear to alter carriage of filamentous fungi in the upper airways. Pathogenic filamentous fungi were only rarely isolated, and this rate did not increase with prophylaxis. Resistance to polyene antifungals (nystatin, amphotericin B) or to ketoconazole did not occur as a result of prophylaxis.

Zusammenfassung: Untersuchung über die Pilzflora im Oropharynx und im vorderen Nasenraum unter dem EinfluB einer prophylaktischen antimykotischen Behandlung. 20 Patienten erhielten Nystatin und 19 Patienten Ketoconazol. Wöchentliche Kontrollkulturen wurden in der Nystatin-Gruppe über einen durchschnittlichen Zeitraum von 27,1 $\pm 4,8$ Tagen und in der Ketoconazol-Gruppe über $44,0 \pm 6,7$ Tage durchgefïhrt. Zu Beginn der Untersuchung hatten 63,2\% der Nystatin-Patienten und 77,8 \% der Ketoconazol-Patienten Hefen im Oropharynx. Keines 
der beiden Antimykotika eliminierte die oropharyngeale Hefebesiedlung. Nach 4wöchiger Beobachtung wurden Hefen in der Nystatin-Gruppe bei 76,7 \% und in der Ketoconazol-Gruppe bei $63,6 \%$ im Oropharynx festgestellt. Durch beide Antimykotika wurde jedoch eine Verringerung der kulturell nachweisbaren Hefemengen hervorgerufen. Schimmelpilze fanden sich zu Beginn der Untersuchung bei 42,1 \% der Nystatin-Patienten und bei 33,3\% der KetoconazolPatienten. Unter der prophylaktischen Behandlung war keine Verringerung des Vorkommens derartiger Pilze in den oberen Luftwegen feststellbar. Pathogene Schimmelpilze wurden nur sehr selten isoliert und das Vorkommen dieser Pilze stieg unter der prophylaktischen Behandlung nicht an. Eine Resistenz gegenüber Polyen-Antimykotika (Nystatin, Amphotericin B) oder Ketoconazol trat unter der prophylaktischen Behandlung nicht auf.

\section{Introduction}

Patients with prolonged neutropenia due to cancer chemotherapy are at high risk for developing infections with yeast-like fungi, such as Candida $(4,16)$. Overgrowth of yeasts in the gastrointestinal tract may cause locally severe infections, such as thrush and esophagitis, and may culminate in disseminated infection (20). In an attempt to decrease fungal colonization and to prevent serious local yeast infections, as well as disseminated candidiasis, many centers routinely use polyene or imidazole antifungal agents prophylactically $(3,5,20)$.

Ketoconazole is an imidazole which has been shown to be effective in the treatment of chronic mucocutaneous candidiasis (17). It is attractive for use as a prophylactic agent in cancer patients because it is easily administered orally and has minimal toxicity.

This study was undertaken 1) to assess the efficacy of ketoconazole versus nystatin in the prevention of infection with yeast-like fungi in neutropenic patients and 2) to study the effect of ketoconazole and nystatin on the fungal flora of the oropharynx and anterior nares. We were interested in the possible emergence of potentially pathogenic filamentous fungi or the development in yeasts of resistance to antifungal drugs during prophylaxis. A prior report documented those aspects of the study dealing with the clinical efficacy of ketoconazole versus nystatin in preventing fungal infections (14); this report details the studies of fungal colonization and antifungal drug susceptibility.

\section{Materials and Methods}

\section{Patients}

Between March 1982 and March 1983, all patients over the age of 16 hospitalized at the University of Michigan Hospital with acute leukemia or lymphoma, which was to be treated with chemotherapy leading to severe neutropenia, were eligible for this study. None of the patients had received systemic antifungal therapy prior to entering the study. Patients were treated in single rooms while hospitalized. Special isolation precautions were not employed, and regular hospital food was served.

Patients were randomized to receive either ketoconazole, $200 \mathrm{mg}$ daily, or nystatin, 500,000 units, taken as a swish and swallow preparation four times daily. Patients received prophylactic treatment throughout the entire period of expected neutropenia ( $\mathrm{PMN}<500$ / $\mu 1)$, including outpatient days.

\section{Fungal surveillance cultures}

Surveillance cultures for fungi were obtained from the oropharynx and anterior nares prior to starting prophylaxis and every week thereafter while on the study. The anterior nares were sampled with cotton swabs, which were then placed immediately into Stuart's transport medium; cultures of the oropharynx were obtained with a gargle of $5 \mathrm{ml}$ of sterile $0.9 \%$ saline. 
Within an hour of collection, all specimens were inoculated, using the four-quadrant method, onto plates containing Sabouraud dextrose agar and Sabouraud dextrose agar with chloramphenicol (GIBCO Inc., Grand Island, NY) (13). The plates were incubated at $25^{\circ} \mathrm{C}$ and examined weekly for 4 weeks. The growth of yeasts was graded as rare, few, moderate, or abundant by standard criteria (13). The growth of filamentous fungi could not be quantitated accurately in this manner and simply was noted as present or absent.

\section{Identification of fungi}

Yeast-like organisms were identified by using the API Clinical Yeast System (Analytab Products, Inc., Plainview, NY) and germ tube formation (7). Filamentous fungi were identified by hyphal and conidial morphology and color using tease-mount preparations, microslide cultures, and differential media for Aspergillus $(8,18)$.

\section{Antifungal susceptibility studies}

An agar dilution replicate plate method was used for testing the susceptibility of the isolates to ketoconazole, nystatin, and amphotericin B. Ketoconazole powder (Janssen Pharmaceutica, Inc., New Brunswick, NJ), nystatin powder (Squibb, Inc., Princeton, NJ), and amphotericin B powder (Squibb, Inc.) were each dissolved in $100 \%$ dimethyl sulfoxide (DMSO) yielding stock solutions of $1000 \mu \mathrm{g} / \mathrm{ml}$. The drugs were further diluted in sterile distilled water to give concentrations of $0.06 \mu \mathrm{g} / \mathrm{ml}$ to $500 \mu \mathrm{g} / \mathrm{ml}$. The final dilutions of the drugs were made in molten agar to achieve concentrations of $0.006 \mu \mathrm{g} / \mathrm{ml}$ to $50 \mu \mathrm{g} / \mathrm{ml}$ in the assay plates. The agar used for ketoconazole assays was Kimmig agar (E. Merck, Inc., Darmstadt, Federal Republic of Germany), adjusted to $\mathrm{pH}$ 6.5 (19); the agar used for nystatin and amphotericin B studies was antibiotic medium No. 3 in purified agar (Difco, Inc., Detroit, MI).

Organisms were grown overnight in yeast nitrogen base with dextrose (Difco, Inc.) and diluted in $0.9 \% \mathrm{NaCl}$ to a concentration of $5 \times 10^{4}$ organisms $/ \mathrm{ml}$ using a barium standard. Plates containing antifungal drugs of varying concentrations were inoculated with a Steers replicator which delivered $0.003 \mathrm{ml}$ of each test organism. Therefore, the final inoculum was $1.5 \times 10^{2}$ organisms. The plates were incubated $25^{\circ} \mathrm{C}$ for 48 hours. The minimum inhibitory concentration (MIC) was defined as the lowest concentration of drug which prevented visible growth on the plates. The $\mathrm{MIC}^{50}$ was the concentration of drug which inhibited $50 \%$ of the isolates, and the $\mathrm{MIC}^{90}$ was that concentration of drug which inhibited $90 \%$ of the isolates.

\section{Results}

Patients

Forty-three patients were entered into the study. Twenty were randomized to receive ketoconazole; three of this group were excluded from analysis because of poor compliance ( 2 patients) or transfer to another facility within 7 days of beginning the study (1 patient). Twenty-three were randomized to receive nystatin; three were excluded from analysis because of poor compliance (1 patient) or death within 7 days of beginning the study ( 2 patients). In addition, 2 patients who failed on nystatin and who were placed on ketoconazole 2 months and 3 months later, respectively, were included in the ketoconazole group as well as in the nystatin group. Thus, there were 19 patients in the ketoconazole group and 20 patients in the nystatin group who were assessed for fungal colonization.

The mean time over which surveillance cultures were obtained was $27.1 \pm 4.8$ days for the group on nystatin and $44.0 \pm 6.7$ days for the group on ketoconazole. The total number of times cultures were obtained was 77 for those on nystatin and 115 for those on ketoconazole. The patients given nystatin were followed for a shorter period of time and had fewer cultures 
YEAST COLONIZATION

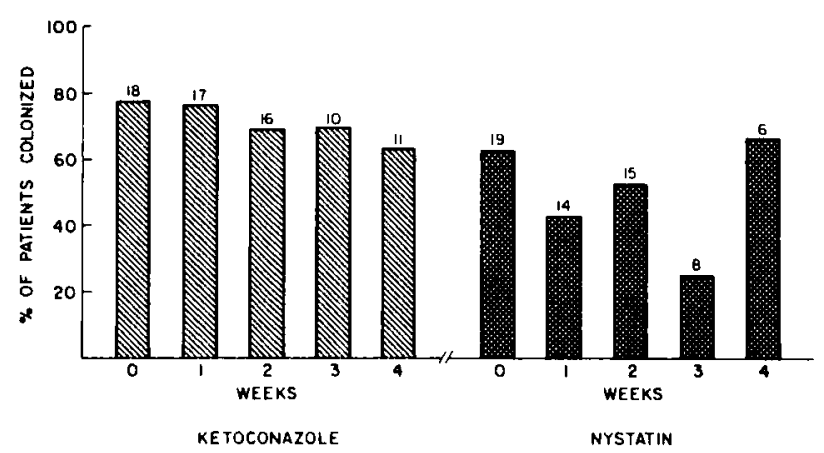

Fig. 1: The percent of patients with oropharyngeal colonization with yeasts before prophylaxis was begun and during the first four weeks of prophylaxis with ketoconazole or nystatin. Numbers above the bars refer to the number of patients from whom surveillance cultures were obtained that week.

Table 1

Yeast-like organisms isolated in surveillance cultures from 19 patients on ketoconazole and 20 patients on nystatin

\begin{tabular}{llc}
\hline \multirow{2}{*}{ Organisms } & \multicolumn{2}{c}{ Number $(\%)$ isolates } \\
& Ketoconazole & Nystatin \\
\hline Candida albicans & $73(74.5)$ & $34(70.8)$ \\
Saccharomyces cerevisiae & $11(11.2)$ & 0 \\
Torulopsis glabrata & $2(2.0)$ & $6(12.5)$ \\
Candida parapsilosis & $5(5.1)$ & 0 \\
Candida tropicalis & $3(3.1)$ & $2(4.2)$ \\
Candida krusei & $3(3.1)$ & $4(8.3)$ \\
Candida guilliermondii & $0(\overline{-})$ & $2(4.2)$ \\
Candida species & $1(1.0)$ & $0-$ \\
Total & 98 & 48 \\
\hline
\end{tabular}

taken due to a higher rate of development of fungal infections ( 9 infections compared with 3 in the ketoconazole group), leading to withdrawal of these patients from the study (14).

\section{Effect of prophylaxis on yeast-like flora}

The percentage of patients whose baseline cultures yielded yeast-like organisms was similar in both groups (Fig. 1). Neither drug eliminated colonization during the first four weeks of surveillance (Fig. 1). By the end of four weeks, $66.7 \%$ of the nystatin group and $63.6 \%$ of the ketoconazole group had yeasts remaining in their oropharynx. However, of those patients who had yeast present in baseline cultures, $66.7 \%$ on nystatin and $57.1 \%$ on ketoconazole showed a fall in the quantity of yeasts grown on successive cultures. Two patients on nystatin and 3 on ketoconazole had abundant yeast growth throughout prophylactic therapy.

The yeast most commonly isolated was Candida albicans, with all other species occurring much less frequently (Tab. 1). Neither drug led to overgrowth by a predominant yeast, such as Torulopsis glabrata or $\mathrm{C}$. tropicalis. On only four occasions did anterior nares cultures yield yeasts; in all four instances, the growth was very scanty and the organism was present in the oropharynx at the same time.

\section{Effect of prophylaxis on filamentous fungal flora}

The percentage of patients whose baseline cultures yielded filamentous fungi was similar in both groups (Fig. 2). Neither drug eliminated carriage of filamentous fungi nor enhanced 
Fig. 2: The percent of patients with anterior nares or oropharyngeal colonization with filamentous fungi before prophylaxis was begun and during the first four weeks of prophylaxis with ketoconazole or nystatin. Numbers above the bars refer to the number of patients from whom surveillance cultures were obtained that week.

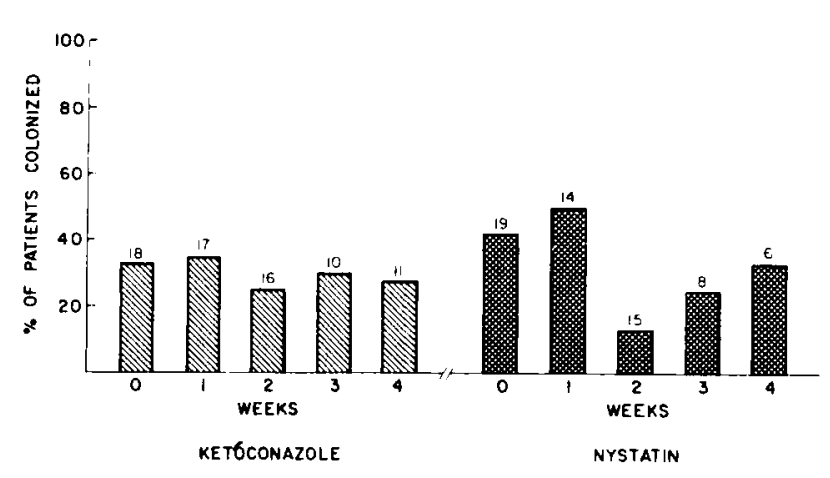

Table 2

Filamentous fungi isolated in surveillance cultures from 19 patients on ketoconazole and 20 patients on nystatin

\begin{tabular}{lcc}
\hline \multirow{2}{*}{ Organisms } & \multicolumn{2}{c}{ Number (\%) isolates } \\
& Ketoconazole & Nystatin \\
\hline Cladosporium & $11(22.0)$ & $8(18.6)$ \\
Penicillium & $5(10.0)$ & $5(11.6)$ \\
Alternaria & $7(14.0)$ & $2(4.7)$ \\
Basidiomycetes & $1(2.0)$ & $7(16.3)$ \\
Aspergillus versicolor & $6(12.0)$ & $5(11.6)$ \\
Aspergillus fumigatus & $1(2.0)$ & 0 \\
Aspergillus niger & $1(2.0)$ & $1(2.3)$ \\
Rhizopus & $1(2.0)$ & $1(2.3)$ \\
Other Aspergillus species & $6(12.0)$ & $5(11.6)$ \\
Other filamentous fungi & $11(22.0)$ & $9(21.0)$ \\
Total & 50 & 43 \\
\hline
\end{tabular}

their growth during the first four weeks of surveillance (Fig. 2). Seventy percent of the positive cultures were from the anterior nares in both patient groups. The organisms isolated were almost entirely commensal organisms; Aspergillus niger was isolated twice, A. fumigatus only once, and A. flavus was not found in any culture (Tab. 2).

\section{Antifungal susceptibility studies}

Comparison of $\mathrm{MIC}^{50}$ and the $\mathrm{MIC}^{90}$ for each drug showed nodifferences between the yeasts isolated in baseline cultures and those isolated during the course of prophylaxis with either nystatin or ketoconazole (Tab. 3).

\section{Discussion}

This study was concerned with finding a prophylactic antifungal regimen which would be efficacious in eliminating yeast infections in neutropenic patients. It was of interest to determine if efficacy could be related to decreasing colonization by yeasts in the oropharynx. Also, we felt it important to document the consequences of long-term prophylaxis, with regard to overgrowth of filamentous fungi, such as Aspergillus, and development of resistance to ketoconazole or polyene antifungal agents.

mykosen 27, Heft 4 (1984) 


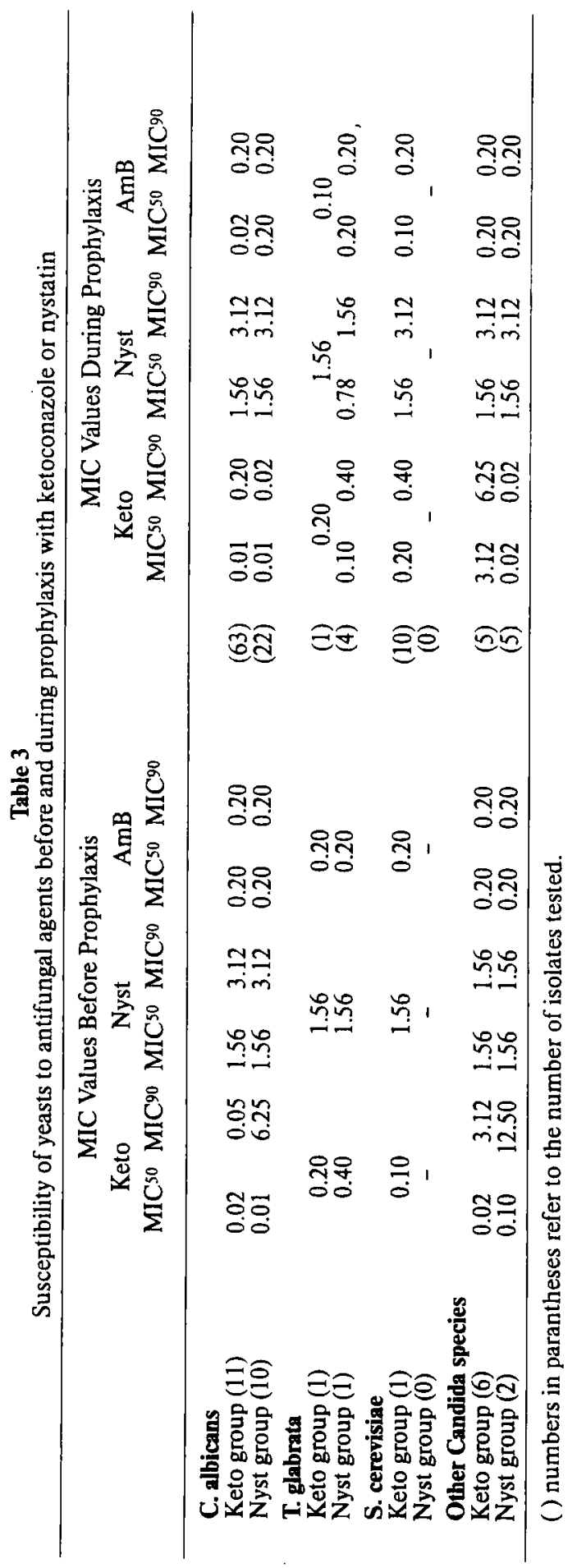

mykosen 27, Heft 4 (1984) 
The clinical aspects of this study, reported previously, showed that ketoconzole was slightly more efficacious than nystatin in preventing serious local yeast infections, such as thrush, esophagitis, and vaginitis (14). However, clinical efficacy of ketoconazole was not associated with eradication of fungal colonization in the oropharynx. Other studies with ketoconazole, as well as those with miconazole or amphotericin B, have shown this dissociation between clinical efficacy and effect on colonization $(6,10,20)$. Our study, as well as prior ones using other antifungal agents, has shown that the quantity of yeasts in the oropharynx does decrease with prophylaxis even though eradication of yeasts does not occur $(10,20)$.

Overgrowth by strains of yeasts, such as T. glabrata, which may be more resistant to ketoconazole, was noted in one preliminary study of ketoconazole prophylaxis in neutropenic patients (9). However, our study failed to show emergence of $T$. glabrata or other resistant yeasts. The few patients who were colonized with $T$. glabrata carried this yeast before prophylaxis and demonstrated persistence of the organism in the oropharynx in successive cultures.

Likewise, another preliminary report noted the emergence of and infection with filamentous fungi, such as Aspergillus, in patients on ketoconazole prophylaxis (1). Our patients did not show an increase in colonization with filamentous fungi while on prophylaxis. Pathogenic Aspergillus species such as A. fumigatus and A. flavus, were rarely isolated in our patients. Colonization with pathogenic Aspergillus species is probably most dependent on environmental sources (2) and is uncommon in the absence of such a source (15). Previous surveillance cultures in neutropenic patients at our institution revealed a seasonal variation in colonization with filamentous fungi, with more isolates recovered in the summer months (15).

Prophylactic therapy with ketoconazole or nystatin did not lead to the development of ketoconazole-resistant or polyene-resistant yeasts. Polyene resistance has been reported in $7.4 \%$ of isolates from oncology patients at one center (11), but all isolates were from patients who had received systemic amphotericin B, as well as nystatin prophylaxis. Oral nystatin alone did not lead to emergence of resistance in our population. The development of resistance to ketoconazole has been reported only rarely (12). Our study confirms that prophylaxis in neutropenic cancer patients for as long as 4 months is not associated with the development of ketoconazole resistant organisms.

Acknowledgements: This study was supported by the Veterans Administration Research Service. We thank Ms. Jeanne Mioduszewski for her help in obtaining surveillance cultures. We thank Dr. S. Shadomy for advice regarding antifungal susceptibility studies.

\section{References}

1. Acuna, G., D. J. Winston \& L. S. Young (1981): Ketoconazole prophylaxis of fungal infections in the granulocytopenic patient. 21 st Interscience Conference on Antimicrobial Agents and Chemotherapy. Chicago, IL: American Society for Microbiology, Abst. No. 852.

2. Aisner, J., J. Murillo, S. C. Schimpff \& A. C. Steere (1979): Invasive aspergillosis in acute leukemia: Correlation with nose cultures and antibiotic use. Ann. Intern. Med 90,4-9.

3. Bodey, G. P. \& B. Rosenbaum (1974): Effect of prophylactic measures on the microbial flora of patients in protected environment units. Medicine 53, 209-228.

4. Bodey, G. P., R. Bolivar \& V. Fainstein (1982): Infectious complications in leukemic patients. Sem. Hematol. 19, 193-226.
5. Brincker, H. (1978): Prophylactic treatment with miconazole in patients highly predisposed to fungal infection. Acta Med. Scand. 204, 123-128.

6. Brincker, H. (1983): Prevention of mycosis in granulocytopenic patients with prophylactic ketoconazole treatment. Mykosen 26, 242- 247.

7. Buesching, W. J., K. Kurek \& G. D. Roberts (1979): Evaluation of the modified API 20C system for identification of clinically important yeasts. J. Clin. Microbiol. 9, 565-569.

8. Campbell, M. C. \& J. L. Stewart (1980): The Medical Mycology Handbook. New York: John Wiley and Sons.

9. de Jongh, C., R. Finley, J. Joshi, K. Newman, P. Wiernik \& S. Schimpff (1982): A comparison of ketoconazole to nystatin: Prophylaxis 
of fungal infection in neutropenic patients. 22nd Interscience Conference on Antimicrobial Agents and Chemotherapy. Miami, FL: American Society for Microbiology, Abst. No. 497.

10. de Vries-Hospers, H. G., N. H. Mulder, D. T. Sleijfer \& H. K. F. van Saene (1982): The effect of amphotericin B lozenges on the presence and number of Candida cells in the oropharynx of neutropenic leukemia patients. Infection 10, 71-75.

11. Dick, J. D., W. G. Merz \& R. Saral (1980): Incidence of polyene-resistant yeasts recovered from clinical specimens. Antimicrob. Ag. Chemother. 18, 158-163.

12. Horsburgh, C. R. \& C. H. Kirkpatrick (1983): Long-term therapy of chronic mucocutaneous candidiasis with ketoconazole: Experience with twenty-one patients. Amer. J. Med. 74, 23-29.

13. Isenberg, H. D., J. A. Washington, A. Balows \& A. C. Sonnenwirth (1980): Collection, handling and processing of specimens. In: Balows, A., W. J. Hausler \& J. P. Truant (eds.) Manual of Clinical Microbiology, 3 rd edition Washington, DC: American Society for Microbiology. p. 52-82.

14. Jones, P. G., C. A. Kauffman, L. S. McAuliffe, M. K. Liepman \& A. G. Bergman: Efficacy of ketoconazole versus nystatin for the prevention of fungal infections in neutropenic patients. Arch. Intern. Med. (in press).

15. Kauffman, C. A., M. K. Liepman, A. G. Bergman \& J. Mioduszewski (1983): Trimetho- $\mathrm{prim} /$ sulfamethoxazole prophylaxis in neutropenic patients: Reduction of infections and effect on bacterial and fungal flora. Amer. J. Med. 74, 599-607.

16. Meunier-Carpentier, F., T. E. Kiehn \& D. Armstrong (1981): Fungemia in the immunocompromised host. Changing patterns, antigenemia, high mortality. Amer. J. Med. 71, 363-370.

17. Petersen, E. A., D. W. Alling \& C. H. Kirkpatrick (1980): Treatment of chronic mucocutaneous candidiasis. Ann. Intern. Med. 93, 791-795

18. Raper, K. B. \& D. I. Fennell (1977): The Genus Aspergillus. Huntington, NY: Robert E. Kreiger Co.

19. Shadomy, S., D. M. Dixon \& R. May (1982): A comparison of bifonazole (Bay H 4502) with clotrimazole in vitro. Sabouraudia. 20, 313-323.

20. van der Waaij, D., J. M. Vossen, C. A. Hartgrink \& H. O. Nieweg (1979): Polyene antibiotics in the prevention of Candida albicans colonization in the digestive tract of patients with severely decreased resistance to infections. In: van der Waaij, D. \& J. Verhoef (eds.) New criteria for antimicrobial therapy: Maintenance of digestive tract colonization resistance. Amsterdam: Excerpta Medica, 135-144.

Address: Dr. Carol A. Kauffman, Medical Service, VA Medical Center, Ann Arbor, MI 48105. 